\title{
Dimethylcarbonate for eco-friendly methylation reactions
}

\author{
S. Memoli ${ }^{a}$, M. Selva ${ }^{b}$, P. Tundo ${ }^{b, *}$ \\ a Interuniversity Consortium "Chemistry for the Environment", Via della Libertà 5/12, 30175 Venice - Marghera, Italy \\ ${ }^{\mathrm{b}}$ Department of Environmental Science, Cà Foscari University, Dorsoduro 2137, 30123 Venice, Italy
}

\begin{abstract}
Dimethylcarbonate (DMC), an environmentally friendly substitute for dimethylsulfate and methyl halides in methylation reactions, is a very selective reagent. Both under gas-liquid phase transfer catalysis (GL-PTC) and under batch conditions, with potassium carbonate as the catalyst, the reactions of DMC with methylene-active compounds (arylacetonitriles and arylacetoesters, aroxyacetonitriles and methyl aroxyacetates, benzylaryl- and alkylarylsulphones) produce monomethylated derivatives, with a selectivity not previously observed (i.e., $>99 \%$ ). The highly selective $O$-methylation of phenols and $p$-cresols by DMC is also attained by a new methodology using a continuous fed stirred tank reactor (CSTR) filled with a catalytic bed of polyethyleneglycol (PEG) and potassium carbonate. (C) 2001 Elsevier Science Ltd. All rights reserved.
\end{abstract}

Keywords: Green chemistry; Mono- $C$-methylations; $O$-methylations; GL-PTC; CSTR

\section{Introduction}

Starting from 1983, when Enichem (Italy) first developed a dimethylcarbonate (DMC) production process involving the metal-catalysed oxidative carbonylation of methanol (Romano et al., 1979; Romano, 1993), interest in DMC is growing faster and faster.

The oxidative carbonylation process avoids the traditional use of phosgene as raw material, a process which brings about co-production of $\mathrm{HCl}$, or chloride salts, and which affords a product contaminated by toxic, corrosive, chlorinated impurities.

On the contrary, high selectivity and high purity of the product are obtained in the oxidative carbonylation of methanol. The only co-products formed are water and $\mathrm{CO}_{2}$ which is generated from $\mathrm{CO}$ in substantial amounts in the presence of the water.
Due to its clean production technology and unique properties, DMC has found applications in many industrial branches; examples are its use as solvent in a process for deasphalting and demetallating a residue from crude oil distillation; as a lubricant fluid; as a component of oxygenated gasoline or as an expanding system for polyurethane foams.

In addition, DMC is a non-toxic building block that can be used in organic syntheses as a green substitute for toxic and corrosive reagents such as phosgene, dimethylsulfate and methyl iodide (Tundo et al., 1988; Lissel et al., 1989).

In fact, DMC exhibits versatile chemical reactivity (Tundo, 1991; Ono, 1997). Depending on the experimental conditions, it may act as a methylating agent (Eq. (1)), in the place of dimethylsulfate (Eq. (2)) and methyl iodide (Eq. (3)) or as a carboxymethylating agent (Eq. (4)), in the place of phosgene (Eq. (5)).

$$
\begin{aligned}
\mathrm{PhOH}+\mathrm{CH}_{3} \mathrm{OCOOCH}_{3} \rightarrow & \mathrm{PhOCH}_{3}+\mathrm{CO}_{2} \\
& +\mathrm{CH}_{3} \mathrm{OH}
\end{aligned}
$$

\footnotetext{
${ }^{*}$ Corresponding author. Fax: +39-041-2578620.

E-mail address: tundop@unive.it (P. Tundo).
} 


$$
\begin{aligned}
& \mathrm{PhOH}+\left(\mathrm{CH}_{3}\right)_{2} \mathrm{SO}_{4}+\mathrm{NaOH} \\
& \quad \rightarrow \mathrm{PhOCH}_{3}+\mathrm{NaCH}_{3} \mathrm{SO}_{4}+\mathrm{H}_{2} \mathrm{O}
\end{aligned}
$$

$$
\begin{aligned}
\mathrm{PhOH}+\mathrm{CH}_{3} \mathrm{I}+\mathrm{NaOH} \rightarrow & \mathrm{PhOCH}_{3}+\mathrm{NaI} \\
& +\mathrm{H}_{2} \mathrm{O}
\end{aligned}
$$

$$
\begin{aligned}
& \mathrm{ROH}+\mathrm{CH}_{3} \mathrm{OCOOCH}_{3} \rightleftarrows \mathrm{ROCOOCH}_{3} \\
& +\mathrm{CH}_{3} \mathrm{OH}
\end{aligned}
$$

$$
\begin{aligned}
2 \mathrm{ROH}+\mathrm{COCl}_{2}+2 \mathrm{NaOH} \rightleftarrows & \mathrm{ROCOOR}+2 \mathrm{NaCl} \\
& +2 \mathrm{H}_{2} \mathrm{O}
\end{aligned}
$$

Both reactions (methylation and carboxymethylation) occur in the presence of a weak base (usually an alkaline carbonate) that provides nucleophile activation. The nucleophilic anion may react at one of the two carbon centers of DMC, the carbonyl group or the methyl group.

In particular, when the reaction is performed under refluxing conditions $\left(T=90^{\circ} \mathrm{C}\right)$, the nucleophilic anion attacks the acyl carbon giving the transesterification product and the methoxide anion as the leaving group $\left(\mathrm{B}_{\mathrm{Ac}} 2\right.$ mechanism). This latter provides further substrate activation, so that only catalytic amounts of the base are required.

When operating at high temperatures $\left(T \geqslant 160^{\circ} \mathrm{C}\right)$, the nucleophilic anion attacks the methyl group of the organic carbonate $\left(\mathrm{B}_{\mathrm{Al}} 2\right.$ mechanism). In such conditions, the leaving group (methoxycarbonate anion, $\mathrm{CH}_{3} \mathrm{OCOO}^{-}$) is not stable, and it rapidly decomposes into methoxide anion and $\mathrm{CO}_{2}$. In this case also, the base is used in catalytic amounts.

While carboxymethylation is an equilibrium reaction, methylation is not.

Both carboxylation with phosgene and methylation with dimethylsulfate or methyl iodide generate stoichiometric quantities of the inorganic salt as by-products, a base being used as a reagent. Instead, the corresponding processes of DMC do not involve disposal problems since no salts are produced and the only by-product, methanol, can be easily recycled in the DMC production plant (Delledonne et al., 1995).

Methylation reactions with DMC can be profitably carried out both under gas-liquid phase-transfer catalysis (GL-PTC) conditions (Tundo, 1979; Tundo et al., 1989) and batchwise (Selva et al., 1994; Tundo and Selva, 1995).

In the former, an activated anion and a gaseous organic substrate react under a continuous flow mode, in the presence of a phase transfer (PT) catalyst immobilised on a solid bed. Both the reagent and the products are in the gas phase (Fig. 1).

In a typical configuration, a continuous feeding of liquid reagents is sent to a cylindrical catalytic column (plug-flow reactor) where it is vaporised. Gaseous products are condensed and collected at the outlet of the reactor (Fig. 2).

Although other PT catalysts are more active (phosphonium salts, crown ethers, cryptands), polyethyleneglycols (PEGs) are frequently used in organic syntheses

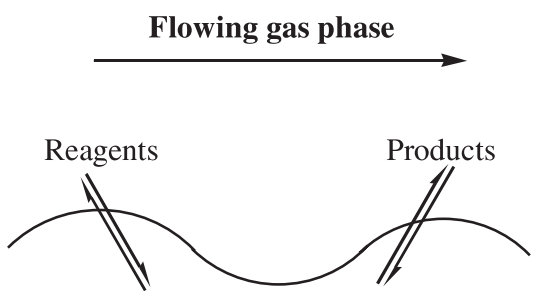

Liquid Phase
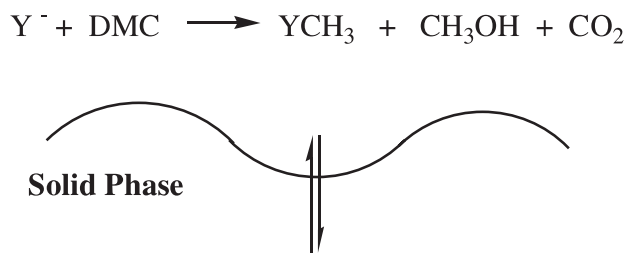

Anion exchange

Fig. 1. Under GL-PTC conditions, the reaction takes place in the liquid film of PEG covering the solid particles of the base.

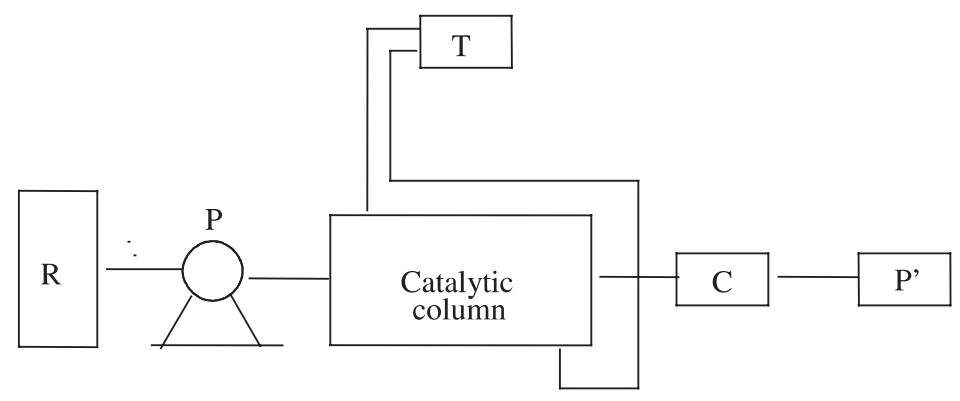

Fig. 2. GL-PTC apparatus. R, reagent's reservoir; P, metering pump; T, thermostat; C, condenser; $\mathrm{P}^{\prime}$, product store. 
because they are thermally stable, non-toxic and inexpensive (Lee and Chang, 1978; Shirai and Smid, 1980).

In the methylation reactions by $\mathrm{DMC}$, the solid bed is composed of $\mathrm{K}_{2} \mathrm{CO}_{3}$ as the basic catalyst coated with a film of PEG 6000 (0.5-5\% molar equivalents). At the operating temperature $\left(180^{\circ} \mathrm{C}\right)$, the PEGs are in the molten state. They increase the basic strength of the alkaline carbonate by complexing the metal cation; thus, the actual nucleophile is formed by anionic exchange and reacts with DMC in the liquid organic phase provided by the film of PEGs (Fig. 1). The lack of solvation in the organic phase allows the anion to be very active in $\mathrm{S}_{\mathrm{N}}$ 2-type reactions.

As DMC boils at $90^{\circ} \mathrm{C}$ and acts as a methylating agent only when operating at high temperature, the batch reactions are necessarily performed in a stainless steel autoclave heated by an electrical oven. Batchwise methylations by DMC require no PT catalysts and the base $\left(\mathrm{K}_{2} \mathrm{CO}_{3}\right)$ can be used in catalytic amounts $(0.05$ molar equivalents). DMC can be used in a large excess (10-30 molar excess), acting at the same time as the solvent and the reagent.

\section{Selective monomethylation reactions of methylene- active compounds}

Monomethylation reactions of methylene-active compounds are not a one-step process in the industry because of the relevant quantity of dimethyl derivatives obtained with the usual methylating agents (Makosza, 1975). However, either under GL-PTC or batch conditions, the reactions of DMC with methylene-active compounds produce monomethylated derivatives, with a selectivity not previously observed.

\subsection{Arylacetonitriles and arylacetoesters}

The mono-methylation reactions of arylacetonitriles and arylacetoesters are noteworthy for the production of 2-arylpropionic acid, a class of compounds of wide pharmaceutical interest, being intermediates for the production of anti-inflammatory drugs like ketoprofen, naproxen, etc.

The methylation process with DMC (Eq. (6)) affords the corresponding mono- $C$-methylderivatives with unprecedented selectivity.

$$
\begin{aligned}
& \mathrm{ArCH}_{2} \mathrm{X}+\mathrm{CH}_{3} \mathrm{OCOOCH}_{3}
\end{aligned}
$$

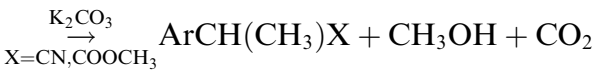

The results obtained in the batchwise methylation by DMC of a number of arylacetonitriles and methylarylacetates are reported in Table 1 (Selva et al., 1994).
Experimental evidences (detection of $\mathrm{ArCH}(\mathrm{CO}$ $\left.\mathrm{OCH}_{3}\right) \mathrm{X}$ and $\mathrm{ArC}\left(\mathrm{CH}_{3}\right)\left(\mathrm{COOCH}_{3}\right) \mathrm{X}$ as reaction intermediates) strongly support the hypothesis that the high monomethyl selectivity is not due to the $\mathrm{S}_{\mathrm{N}} 2$ displacement of the nucleophile $\mathrm{ArCH}^{(-)} \mathrm{X}$ on DMC (Tundo et al., 2000). Instead, DMC acts first as a carboxymethylating agent $\left(\mathrm{B}_{\mathrm{Ac}} 2\right.$ mechanism) which allows the protection of the methylene-active derivatives and permits nucleophilic displacement $\left(\mathrm{B}_{\mathrm{Al}} 2\right)$ to occur with another molecule of DMC. This pattern shows the very peculiar action of the methoxycarbonyl group, that plays a two-fold role in (i) increasing the acidity of $\mathrm{ArCH}\left(\mathrm{COOCH}_{3}\right) \mathrm{X}$ favouring the formation of the corresponding anion and (ii) acting as a protecting group which prevents further methylation. The key step is the attack of the anion $\mathrm{ArC}^{(-)}\left(\mathrm{COOCH}_{3}\right) \mathrm{X}$ on the DMC molecule.

As evidence, the reaction of the potassium salt of 2-carboxymethylphenylacetonitrile $\quad\left[\mathrm{K}^{(+)} \mathrm{PhC}^{(-)}(\mathrm{CO}\right.$ $\left.\mathrm{OCH}_{3}\right) \mathrm{CN}$ ] with DMC yields $\mathrm{PhC}\left(\mathrm{CH}_{3}\right)\left(\mathrm{COOCH}_{3}\right) \mathrm{CN}$ as the sole product. For this reaction, the activation energy evaluated using the Arrhenius equation was found to be $23.4 \mathrm{kcal} \mathrm{mol}^{-1}$, higher than observed with usual displacements (Axelson et al., 1995).

\subsection{Aroxyacetonitriles and methyl aroxyacetates}

According to the mechanism depicted for arylacetonitriles, the methylation of aroxyacetonitriles and methyl aroxyacetates also proceeds with selectivity up to $99 \%$ in the mono-methyl derivatives: 2-aroxy propionitriles and methyl 2-aroxypropionates are the corresponding products (Eq. (7)) (Bomben et al., 1995).

$$
\begin{aligned}
& \underset{\mathrm{ArOCH}}{\mathrm{A}=\mathrm{CN}, \underset{\mathrm{COOCH}}{3}}+\mathrm{CH}_{3} \mathrm{OCOOCH}_{3} \\
& \underset{\text { base }}{\longrightarrow}
\end{aligned}
$$

The reaction proceeds under batch conditions, at 180 $200^{\circ} \mathrm{C}$, in the presence of $\mathrm{K}_{2} \mathrm{CO}_{3}$ or $t$ - $\mathrm{BuOK}$ as the catalyst. Although DMC acts as both the alkylating agent and the solvent (30 molar excess with respect to the substrate), no dialkylated by-products are formed. The results of the methylation of different methyl aryloxyacetates and aryloxyacetonitriles are reported in Table 2 .

In general, the reaction occurs faster on nitriles than on esters, which require higher temperatures and longer reaction times for the conversion to be completed (compare entries 1 and 4, 2 and 5 and 3 and 6, respectively). This behaviour well parallels the trend already observed in the methylation reactions of arylacetonitriles and alkyl arylacetates by DMC, esters always being less reactive than nitriles. Under the reported basic conditions, the higher reactivity of the nitriles may be 
Table 1

Selective mono-methylation of arylacetonitriles and methyl arylacetates by dimethylcarbonate ${ }^{\mathrm{a}}$

\begin{tabular}{|c|c|c|c|c|c|}
\hline \multicolumn{2}{|c|}{$\begin{array}{l}\text { Substrate } \\
\mathrm{ArCH}_{2} \mathrm{X}\end{array}$} & \multirow{2}{*}{$\begin{array}{l}\mathrm{X} \\
\mathrm{CN}\end{array}$} & \multirow{2}{*}{$\begin{array}{l}\text { Reaction time }(\mathrm{h}) \\
3.75\end{array}$} & \multirow{2}{*}{$\begin{array}{l}\text { Conversion }^{\mathrm{b}}(\%) \\
100\end{array}$} & \multirow{2}{*}{$\begin{array}{l}\text { Product }(\% \text { yield })^{\mathrm{c}} \\
\operatorname{ArCH}\left(\mathrm{CH}_{3}\right) \mathrm{X} \\
\mathrm{Ar}=\mathrm{Ph}(90)\end{array}$} \\
\hline 1 & $\mathrm{Ar}=\mathrm{Ph}$ & & & & \\
\hline 2 & $\mathrm{Ar}=o-\mathrm{MeOC}_{6} \mathrm{H}_{5}$ & $\mathrm{CN}$ & 14.5 & 100 & $\mathrm{Ar}=o-\mathrm{MeOC}_{6} \mathrm{H}_{5}$ \\
\hline 3 & $\mathrm{Ar}=m-\mathrm{MeOC}_{6} \mathrm{H}_{5}$ & $\mathrm{CN}$ & 3.5 & 100 & $\mathrm{Ar}=m-\mathrm{MeOC}_{6} \mathrm{H}_{5}(80)$ \\
\hline 4 & $\mathrm{Ar}=p-\mathrm{MeOC}_{6} \mathrm{H}_{5}$ & $\mathrm{CN}$ & 4.75 & 99 & $\mathrm{Ar}=p-\mathrm{MeOC}_{6} \mathrm{H}_{5}(88)$ \\
\hline 5 & $\mathrm{Ar}=o-\mathrm{MeC}_{6} \mathrm{H}_{5}$ & $\mathrm{CN}$ & 7.5 & 99 & $\mathrm{Ar}=o-\mathrm{MeC}_{6} \mathrm{H}_{5}$ \\
\hline 6 & $\mathrm{Ar}=p-\mathrm{MeC}_{6} \mathrm{H}_{5}$ & $\mathrm{CN}$ & 7.5 & 98 & $\mathrm{Ar}=o-\mathrm{MeOC}_{6} \mathrm{H}_{5}(80)$ \\
\hline 7 & $\mathrm{Ar}=p-\mathrm{ClC}_{6} \mathrm{H}_{5}$ & $\mathrm{CN}$ & 2.25 & 100 & $\mathrm{Ar}=p-\mathrm{ClC}_{6} \mathrm{H}_{5}$ \\
\hline 8 & $\mathrm{Ar}=p-\mathrm{FC}_{6} \mathrm{H}_{5}$ & $\mathrm{CN}$ & 2.75 & 100 & $\mathrm{Ar}=p-\mathrm{FC}_{6} \mathrm{H}_{5}$ \\
\hline 9 & $\mathrm{Ar}=m-\mathrm{MeO}_{2} \mathrm{CC}_{6} \mathrm{H}_{5}$ & $\mathrm{CN}$ & 8.00 & 100 & $\mathrm{Ar}=m-\mathrm{MeO}_{2} \mathrm{CC}_{6} \mathrm{H}_{5}$ \\
\hline 10 & $\mathrm{Ar}=\mathrm{Ph}$ & COOMe & 8.00 & 99 & $\mathrm{Ar}=\mathrm{Ph}(80)$ \\
\hline 11 & $\mathrm{Ar}=2-\left(6-\mathrm{MeOC}_{10} \mathrm{H}_{6}\right)$ & COOMe & 6.00 & 100 & $\mathrm{Ar}=2-\left(6-\mathrm{MeOC}_{10} \mathrm{H}_{6}\right)$ \\
\hline
\end{tabular}

${ }^{a}$ All reactions were carried out in an autoclave and using substrate, DMC and $\mathrm{K}_{2} \mathrm{CO}_{3}$ in a 1:18:2 molar ratio, respectively. Entries 1-9: reactions carried out at $180^{\circ} \mathrm{C}$; entries $10-11$ : reactions carried out at $220^{\circ} \mathrm{C}$.

${ }^{\mathrm{b}}$ Conversions determined by GC.

${ }^{\mathrm{c}}$ Yields based on distilled (entries 1-10) or recrystallised (entry 11) products.

Table 2

Reactions of aryloxyacetates and aryloxyacetonitriles with $\mathrm{DMC}^{\mathrm{a}}$

\begin{tabular}{|c|c|c|c|c|c|}
\hline & Substrate & $T\left({ }^{\circ} \mathrm{C}\right)$ & $\begin{array}{l}\text { Reaction } \\
\text { time (h) }\end{array}$ & Conversion $^{\mathrm{b}}(\%)$ & Product $(\%)^{\mathrm{c}}$ \\
\hline 1 & $\mathrm{PhOCH}_{2} \mathrm{COOCH}_{3}$ & 190 & 40 & 99 & $\mathrm{PhOCH}\left(\mathrm{CH}_{3}\right) \mathrm{COOCH}_{3}(94)$ \\
\hline 2 & $p-\mathrm{CH}_{3} \mathrm{C}_{6} \mathrm{H}_{4} \mathrm{OCH}_{2} \mathrm{COOCH}_{3}$ & 190 & 70 & 100 & $p-\mathrm{CH}_{3} \mathrm{C}_{6} \mathrm{H}_{4} \mathrm{OCH}_{2} \mathrm{COOCH}_{3}$ (92) \\
\hline 3 & $m-\mathrm{ClC}_{6} \mathrm{H}_{4} \mathrm{OCH}_{2} \mathrm{COOCH}_{3}$ & 190 & 26 & 100 & $m-\mathrm{ClC}_{6} \mathrm{H}_{4} \mathrm{OCH}\left(\mathrm{CH}_{3}\right) \mathrm{COOCH}_{3}(91)$ \\
\hline 4 & $\mathrm{PhOCH}_{2} \mathrm{CN}$ & 190 & 32 & 100 & $\mathrm{PhOCH}\left(\mathrm{CH}_{3}\right) \mathrm{CN}(69)$ \\
\hline 5 & $p-\mathrm{CH}_{3} \mathrm{C}_{6} \mathrm{H}_{4} \mathrm{OCH}_{2} \mathrm{CN}$ & 180 & 40 & 100 & $p-\mathrm{CH}_{3} \mathrm{C}_{6} \mathrm{H}_{4} \mathrm{OCH}\left(\mathrm{CH}_{3}\right) \mathrm{CN}$ (51) \\
\hline 6 & $m-\mathrm{ClC}_{6} \mathrm{H}_{4} \mathrm{OCH}_{2} \mathrm{CN}$ & 180 & 24 & 100 & $m-\mathrm{ClC}_{6} \mathrm{H}_{4} \mathrm{OCH}\left(\mathrm{CH}_{3}\right) \mathrm{CN}$ (79) \\
\hline 7 & $\mathrm{PhOCH}_{2} \mathrm{COOH}$ & 200 & 48 & 100 & $\mathrm{PhOCH}\left(\mathrm{CH}_{3}\right) \mathrm{COOH}(96)$ \\
\hline
\end{tabular}

${ }^{\text {a }}$ All reaction were carried out in an autoclave using the substrate, DMC and base $\left(\mathrm{K}_{2} \mathrm{CO}_{3}\right)$ in a 1:30:2 molar ratio, respectively.

${ }^{\mathrm{b}}$ By GC analyses.

${ }^{\mathrm{c}}$ Yields based on distilled products.

explained with the easier formation of the corresponding carbanions $\mathrm{ArOCH}^{(-)} \mathrm{CN}$. The unusually high selectivity observed in the mono-methylation of methyl aryloxyacetates and aryloxyacetonitriles may be explicable through the mechanism previously described for the reaction of DMC with methyl arylacetates and arylacetonitriles, where $\operatorname{ArCH}\left(\mathrm{COOCH}_{3}\right) \mathrm{X}$ and $\mathrm{ArC}\left(\mathrm{CH}_{3}\right)$ $\left(\mathrm{COOCH}_{3}\right) \mathrm{X}$ are the key intermediates. In fact, in this case also, the reaction proceeds through the formation of methyl-carboxymethyl intermediates $\operatorname{ArOC}\left(\mathrm{CH}_{3}\right)$ $\left(\mathrm{COOCH}_{3}\right) \mathrm{X}$, these derivatives actually being detectable during the reaction course.

\subsection{Alkylarylsulfones}

Sulfones bearing $\alpha$-methylene groups (benzylaryland alkylarylsulfones: $\mathrm{ArCH}_{2} \mathrm{SO}_{2} \mathrm{Ar}^{\prime}$ and $\mathrm{RCH}_{2}$ $\mathrm{SO}_{2} \mathrm{Ar}^{\prime}$ ) can be effectively mono- $C$-methylated (selectivity $>99 \%$ ) by DMC (Eq. (8)) (Bomben et al., 1997)

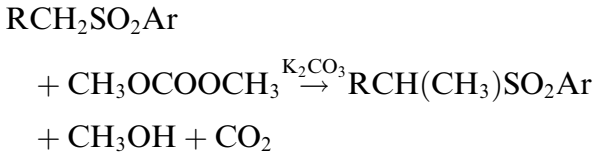

At $\quad 180-210^{\circ} \mathrm{C}$, batchwise mono- $C$-methylations of benzylaryl- and alkylarylsulfones proceed with a selectivity $>99 \%$ (at conversions of $95-99 \%$ ), and afford good to high yields $(77-92 \%)$ of isolated products (Table 3).

A major influence on reactivity arises from the different aryl and alkyl groups directly bound to the methylene reacting group; benzylaryl sulfones (entries $1-5)$ are efficiently mono-methylated at $180^{\circ} \mathrm{C}$ while alkylaryl sulfones (entries 6-8) do not, and actually require a higher reaction temperature $\left(200-210^{\circ} \mathrm{C}\right)$ for the reaction to be completed. Such behaviour seems to be clearly related to the stabilisation of arylsulfonyl carbanions $\mathrm{ArSO}_{2} \mathrm{CH}^{(-)} \mathrm{Ar}^{\prime}$ formed during the reactions, induced by resonance with the adjacent $\mathrm{Ar}^{\prime}$ group. 
Table 3

Reactions of benzylaryl- and alkylarylsulphones with DMC

\begin{tabular}{lllll}
\hline & $\mathrm{R}$ & $\mathrm{Ar}$ & $\begin{array}{l}T \\
\left({ }^{\circ} \mathrm{C}\right)\end{array}$ & $\begin{array}{l}\text { Product } \\
\text { yield }(\%)\end{array}$ \\
\hline 1 & $\mathrm{Ph}$ & $\mathrm{Ph}$ & 180 & 78 \\
2 & $p-\mathrm{ClC}_{6} \mathrm{H}_{5}$ & $\mathrm{Ph}$ & 180 & 76 \\
3 & $p-\mathrm{CH}_{3} \mathrm{C}_{6} \mathrm{H}_{5}$ & $\mathrm{Ph}$ & 180 & 92 \\
4 & $\mathrm{Ph}$ & $p-\mathrm{ClC}_{6} \mathrm{H}_{5}$ & 180 & 80 \\
5 & $p-\mathrm{ClC}_{6} \mathrm{H}_{5}$ & $p-\mathrm{ClC}_{6} \mathrm{H}_{5}$ & 180 & 81 \\
6 & $\mathrm{Ph}$ & $\mathrm{CH}_{3}$ & 200 & 85 \\
7 & $p-\mathrm{ClC}_{6} \mathrm{H}_{5}$ & $\mathrm{CH}_{3}$ & 200 & 77 \\
8 & $p-\mathrm{CH}_{3} \mathrm{C}_{6} \mathrm{H}_{5}$ & $\mathrm{CH}_{3}$ & 210 & 76 \\
\hline
\end{tabular}

The methylation of sulfones of entries $1-5$ follows, in all likelihood, the mechanistic pattern reported for aryland aroxyacetic acid derivatives. Accordingly, the mono-methyl selectivity is explicable through the occurrence of two consecutive nucleophilic displacements, (i) a methoxycarbonylation of the initially formed sulphonyl carbanion $\left[\mathrm{ArSO}_{2} \mathrm{CH}^{(-)} \mathrm{R}\right]$ followed by (ii) a methylation of the resulting intermediate $\left[\mathrm{ArSO}_{2} \mathrm{CH}\left(\mathrm{COOCH}_{3}\right) \mathrm{R}\right]$ yielding the methyl derivative $\left[\mathrm{ArSO}_{2} \mathrm{C}\left(\mathrm{CH}_{3}\right)\left(\mathrm{COOCH}_{3}\right) \mathrm{R}, \mathrm{B}_{\mathrm{Al}} 2\right.$ mechanism] that finally undergoes a de-methoxycarbonylation reaction to give the final product $\left[\mathrm{ArSO}_{2} \mathrm{CH}\left(\mathrm{CH}_{3}\right) \mathrm{R}\right]$.

In this case also, both intermediates $\mathrm{ArSO}_{2} \mathrm{CH}(\mathrm{CO}-$ $\left.\mathrm{OCH}_{3}\right) \mathrm{R}$ and $\mathrm{ArSO}_{2} \mathrm{C}\left(\mathrm{CH}_{3}\right)\left(\mathrm{COOCH}_{3}\right) \mathrm{R}$ are detected during the reaction of $\mathrm{DMC}$ with sulfones of entries $1-5$.

Also methylarylsulfones $\left(\mathrm{ArSO}_{2} \mathrm{CH}_{3}\right)$ react with DMC: the formation of methoxycarbonylated compounds $\left(\mathrm{ArSO}_{2} \mathrm{CH}_{2} \mathrm{COOCH}_{3}\right)$ as intermediates allows the homologation of the methyl group to an $i$-propyl one. Thus, $\mathrm{PhSO}_{2} \mathrm{CH}_{3}$ yields $\mathrm{PhSO}_{2} \mathrm{CH}\left(\mathrm{CH}_{3}\right)_{2}$ and $\mathrm{PhSO}_{2} \mathrm{C}\left(\mathrm{COOCH}_{3}\right)\left(\mathrm{CH}_{3}\right)_{2}(12 \%$ and $81 \%$, respectively; $14 \mathrm{~h}$ at $180^{\circ} \mathrm{C}$; conversion $93 \%$ ). Likewise, $\mathrm{PhCH}_{2} \mathrm{SO}_{2} \mathrm{CH}_{3}$ yields $\mathrm{PhCH}\left(\mathrm{CH}_{3}\right) \mathrm{SO}_{2} \mathrm{CH}\left(\mathrm{CH}_{3}\right)_{2}$ and $\mathrm{PhCH}\left(\mathrm{CH}_{3}\right) \mathrm{SO}_{2} \mathrm{C}\left(\mathrm{COOCH}_{3}\right)\left(\mathrm{CH}_{3}\right)_{2}(14 \%$ and $50 \%$, respectively; $21.5 \mathrm{~h}$ at $180^{\circ} \mathrm{C}$; conversion $98 \%$ ). No $t$-butyl derivatives are produced.

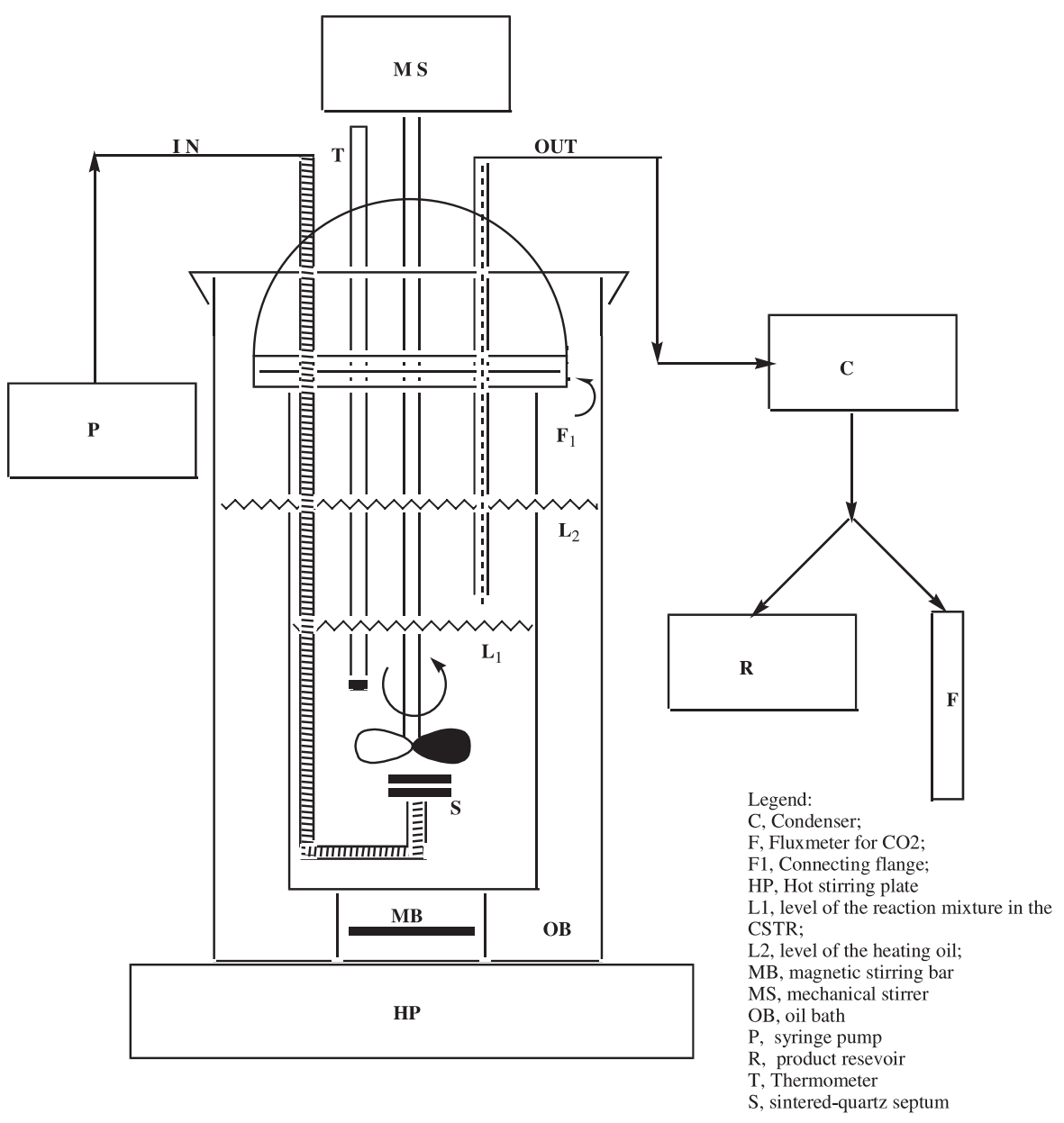

Fig. 3. Schematic plot of the CSTR used for the methylation of phenols by DMC. 


\section{Selective $O$-methylation reactions of phenol}

$O$-Methylated phenols (anisoles) are largely used as antioxidants in oil and grease manufacture, as stabilisers for plastics and as starting material in the production of agrochemicals and dyes. Although anisoles are mostly produced by the use of dimethylsulfate, many alternative methods, dealing with the methylation of methanol in the vapour phase, have been developed (Agayev and Tagiyev, 1992; Bautista et al., 1993). However, in most cases, the selectivity in $O$-methylation products is severely limited by the ring methylation (affording cresols); only a few such procedures (Pierantozzi and Nordquist, 1986; Renaud et al., 1986) claim relevant selectivities $(80-90 \%)$ though at relatively low conversions $(10-30 \%)$.

About 10 years ago, we reported (Tundo et al., 1988) that, under GL-PTC conditions, anisole is obtained as the sole product by feeding, at $180^{\circ} \mathrm{C}$, a mixture of phenol/DMC at 1:2 molar ratio over a catalytic bed composed of 5\% PEG 6000 coated on $\mathrm{K}_{2} \mathrm{CO}_{3}$.

Since then, many authors have studied the DMCmediated methylation of phenol under continuous flow conditions, describing the use of different basic catalytic beds (Fu and Ono, 1993; Fu et al., 1998).

Our group (Bomben et al., 1999) has recently set up a new process for the alkylation of both phenols and $p$ cresols, dealing with a continuously fed stirred tank reactor (CSTR) as an interesting alternative to fixed-bed reactors (GL-PTC).

Stirred tanks are cylindrical glass-made stirred reactors fitted with inlet/outlet glass pipes. The reactant mixture composed of DMC/phenol or $p$-cresol is sent, at atmospheric pressure, through the inlet pipe where it is vaporised and bubbled into the catalytic bed (a stirred slurry of potassium carbonate and PEG 1000). The gaseous stream then passes through the outlet pipe to a condenser, where the products are collected (Fig. 3).

A CSTR is in principle "gradientless"; this means that, when a suitable feeding rate is used, the reagents are perfectly mixed and a constant product concentration is observed both at the outlet and inside the reactor.

The composition of the outlet mixture (Fig. 4(a)) and that of the catalytic bed (Fig. 4(b)), determined for different flow rates $(Q)$, phenol/DMC ratios $(R)$ and reaction temperatures are reported in Fig. 4.

The data indicate that the CSTR is effectively gradientless with $R=0.2$ in the whole range of $Q$ explored and with $R=0.5$ provided that $Q$ is $\leqslant 70 \mathrm{ml} / \mathrm{h}$, but a significant gradient of concentration was observed with $R=0.95$ in spite of the higher temperature $\left(200^{\circ} \mathrm{C}\right.$ vs $\left.160^{\circ} \mathrm{C}\right)$.

In all cases explored, anisole was obtained as the sole product $(100 \%$ selectivity), the remainder being unreacted phenol. The best weight hourly space velocity (WHSV), defined as grams of anisole obtained hourly per gram of catalyst, was found to be $9.0 \times 10^{-2} \mathrm{~h}^{-1}$.

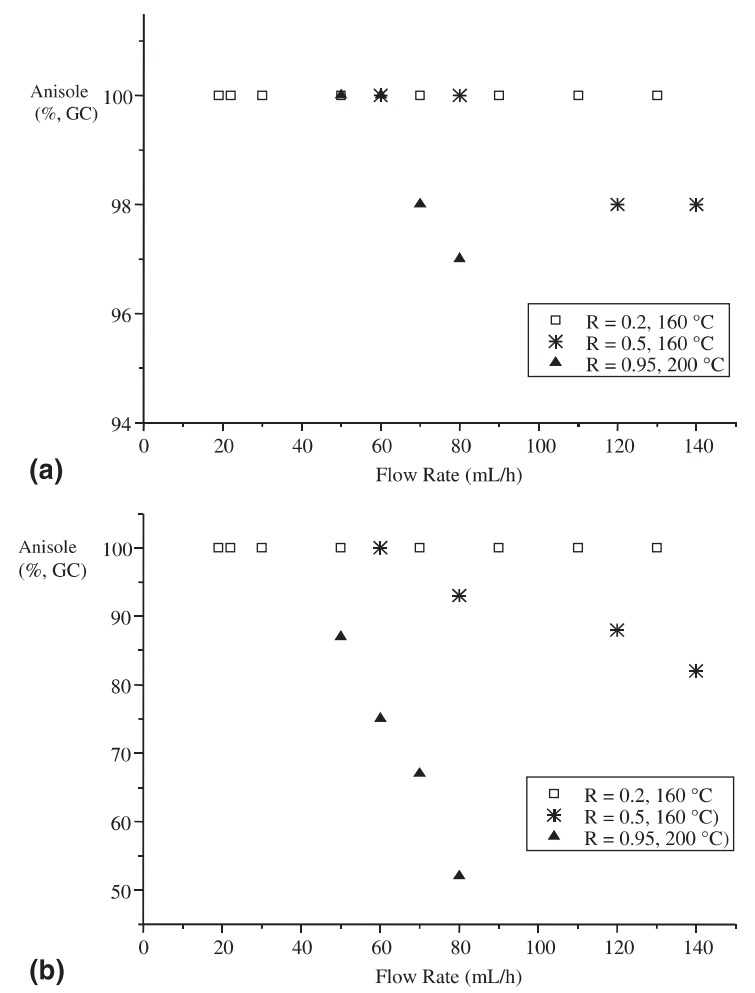

Fig. 4. Anisole amount (a) at the CSTR outlet and (b) inside the catalytic bed of the CSTR using different PhOH: DMC molar ratios $(R)$ and reaction temperatures.

The behaviour of $p$-cresol was similar to that of phenol, the reactor operating gradientless with low $R$ values. Substantially quantitative conversions of $p$-cresol into $p$-methylanisole were attained $(96-100 \%)$ with a WHSV upto $9.5 \times 10^{-2} \mathrm{~h}^{-1}$. As expected, as $R$ was increased, the amount of unreacted $p$-cresol inside the reactor increased as well, at each $Q$ value, though the composition of the outlet mixture still showed $98-100 \%$ of the $O$-methylated compound.

\section{Conclusions}

One of the primary methods for pollution prevention is the adoption of processes that reduce or eliminate the use and generation of hazardous substances. This is the challenge for the future of the chemical industry, its development being mostly linked to how closely environmental needs will be coupled with new ideas in fundamental research.

In this context, substitution of usual methylating agents (dimethylsulfate, methyl halides) with DMC has the following noteworthy advantages:

- non-toxic reagents (DMC) and catalysts $\left(\mathrm{K}_{2} \mathrm{CO}_{3}-\right.$ PEGs) are used; 
- no by-products (inorganic salts) to be disposed of are formed;

- a very high selectivity in mono-methylation (of methylene-active compounds) or $O$-methylation (of phenols) is obtained.

\section{Acknowledgements}

This work was supported by the MURST (Ministero Università e Ricerca Scientifica e Tecnologica) and the Interuniversity Consortium "Chemistry for the Environment", which we gratefully acknowledge.

\section{References}

Agayev, A.A., Tagiyev, D.B., 1992. Alkylation of phenol by methanol on type- $Y$ zeolites. Pet. Chem. 32, 101-105.

Axelson, A.K., Nordahl, A., Carlson, R., 1995. Optimization in organic synthesis - sequential response surface modelling for obtaining kinetic information. 2. An experimental study of the Williamson ether synthesis. J. Chemometrics 9 (6), 441-449.

Bautista, F.M., Campelo, J.M., Garcia, A., Luna, D., Marinas, J.M., Romero, A., Navio, J.A., Macias, M., 1993. Anion treatment $\left(\mathrm{F}^{-}\right.$and $\mathrm{SO}_{4}^{2-}$ ) of $\mathrm{AlPO}_{4}-\mathrm{Al}_{2} \mathrm{O}_{3}$ (25 wt-percent $\mathrm{Al}_{2} \mathrm{O}_{3}$ ) catalysts. 4. Catalytic performance in the alkylation of phenol with methanol. Appl. Catal. A 99, 161-173.

Bomben, A., Marques, C.A., Selva, M., Tundo, P., 1995. Selective mono- $C$-methylation of methyl aryloxyacetates and aryloxyacetonitriles by dimethylcarbonate. Tetrahedron 51, 11573.

Bomben, A., Selva, M., Tundo, P., 1997. Dimethylcarbonate as a methylating agent. The selective mono- $C$-methylation of alkyl aryl sulfones. J. Chem. Res. (S), 448.

Bomben, A., Selva, M., Tundo, P., 1999. A continuous-flow $O$ methylation of phenols with dimethylcarbonate in a CSTR system. Ind. Eng. Chem. Res. 38, 2075-2079.

Delledonne, D., Rivetti, F., Romano, U., 1995. J. Organomet. Chem. 448, C15-C19.

Fu, Y., Baba, T., Ono, Y. Vapor-phase reaction of catechol with dimethylcarbonate. Appl. Catal. A 166, 425-430.

$\mathrm{Fu}$, Z.H., Ono, Y., 1993. Selective $O$-methylation of phenol with dimethyl carbonate over $X$-zeolites. Catal. Lett. 21, 4347.
Lee, D., Chang, V., 1978. Oxidation of hydrocarbons. 8. Use of dimethyl polyethyleneglycol as phase-transfer agent for the oxidation of alkenes by potassium permanganate. J. Org. Chem. 43, 1532-1536.

Lissel, M., Rohani-Dezfull, A.R., Vogt, G., 1989. J. Chem. Res. (M), 2434 .

Makosza, M., 1975. Pure Appl. Chem. 43, 439.

Ono, Y., 1997. Catalysis in the production and reactions of dimethylcarbonate, an environmentally benign building block. Appl. Catal. A 155, 133-166.

Pierantozzi, R., Nordquist, F., 1986. Selective $O$-alkylation of phenol with methanol. Appl. Catal. A 21, 263-271.

Renaud, M., Chantal, P.D., Kalliaguine, S., 1986. Anisole production by alkylation of phenol. Can. Chem. Eng. 64, 787-791.

Romano, U., Rivetti, F., Di Muzio, N., 1979. US Patent. 4, 318, 862, 1981, C.A. 80141.

Romano, U., 1993. Chim. Ind. 72, 18.

Selva, M., Marques, C.A., Tundo, P., 1994. Selective monomethylation of arylacetonitriles and methyl arylacetates by dimethylcarbonate. J. Chem. Soc. Perkin Trans. 1, 1323.

Shirai, M., Smid, J., 1980. Decarboxylation reactions: reactivity of a free carboxylate anion in ethereal solvents. J. Am. Chem. Soc. 102, 2863-2865.

Tundo, P., 1979. Nucleophilic substitution between a gaseous alkyl halide and a solid salt, promoted by a phase transfer catalyst. J. Org. Chem. 44, 2048-2049.

Tundo, P., 1991. Continuous Flow Methods in Organic Synthesis. Ellis Horwood, Chichester, UK.

Tundo, P., Moraglio, G., Trotta, F., 1989. Gas-liquid phase transfer catalysis: a new continuous flow method in organic synthesis. Ind. Eng. Chem. Res. 28, 881-890.

Tundo, P., Selva, M., 1995. Simplify gas-liquid phase transfer catalysis. Chemtech 25 (5), 31-35.

Tundo, P., Selva, M., Memoli, 2000. Dimethylcarbonate as a green reagent. In: ACS. Green Chemistry: Recent Advances in Chemical Syntheses and Processes, in press.

Tundo, P., Trotta, F., Moraglio, G., Ligorati, F., 1988. Continuous-flow processes under gas-liquid phase-transfer (GL-PTC) conditions. The reaction of dialkyl carbonates with phenols, alcohols, and mercaptans. Ind. Eng. Chem. Res. 27, 1565-1571.

Pietro Tundo is a Professor of Organic Chemistry at the University of Venice. He has authored about 120 scientific papers and 25 patents. His research interests include syntheses with low environmental impact, continuous-flow processes in organic synthesis and degradation of toxic compounds. He is the Director of the Interuniversity Consortium "Chemistry for the Environment" (www.unive.it/inca). 